\title{
On the Horns of a Dilemma: Let the Northern White Rhino Vanish or Intervene?
}

\author{
Craig Callender*
}

\section{Introduction}

Rhinos are one of the largest and most charismatic land animals in existence. Second in size among land mammals to only elephants, all five species of the family Rhinocerotidae are in grave danger primarily due to poaching. As such they are the subject of intense international attention in conservation science. In what follows I'll focus on the African white rhino, which is comprised of two subspecies, the southern white rhino (SWR, Ceratotherium simum simum) and the northern white rhino (NWR, Ceratotherium simum cotton). The SWR faced a tight population bottleneck roughly a century ago, but due to conservation efforts it has rebounded and currently numbers $\sim 20,000$ individuals, most residing in South Africa. The NWR, by contrast, has vanished from the wild and is presumably the most endangered mammal in the world. Two females, 20-year-old Fatu and her 30-year-old mother, Najin, are the sole surviving NWRs, both living in the $\mathrm{Ol}$ Pejeta Conservancy in Kenya. The last male, Sudan, died in 2018. Neither surviving females are viable mothers. As a result, the NWR is functionally extinct.

Hope for the NWR now lies in the cells of Fatu and Najin and frozen tissue from the last NWRs. Using advanced reproductive and genetic technologies, conservation science groups throughout the world are trying to produce NWR. Referring to these strategies, hundreds of international news outlets triumphantly proclaim that the NWR can be brought back from extinction, that novel science can save the NWR. There is also a backlash to the project. Gilcrist 2018 asks, "if humans cannot save a species in nature while it is alive, what future for animals that we manufacture? My worry is that they would simply be living museum exhibits, destined to live out their lives in zoos, with habitat loss or poaching preventing life in the wild. Where would this end? Do we want to repopulate the world with lab-produced engineered organisms?" Gilcrist and others echo many of the worries (e.g. Minteer 2019) that arise about projects to make long vanished animals like the mammoth and passenger pigeon de-extinct.

\footnotetext{
${ }^{*}$ Department of Philosophy and Institute for Practical Ethics, UC San Diego
} 
In light of these concerns, I ask whether NWR recovery is worthwhile. Who is the project for? NWR? White rhinos? Researchers? The ecosystem where they could be reintroduced? As we'll see, due to the similarity between the SWR and NWR, the NWR project has an interesting and distinctive philosophical profile, one that raises at once almost every foundational question facing conservation science today. In what follows I pay special attention to the goals of the project, for I think the goal is critical to our assessment of it. Put roughly, my view is that perceived through the lens of many traditional rationales for conservation, it is hard to justify the NWR recovery project; but if viewed through the lens of the value of the technology and good of future generations, then the project has many independent rationales.

\section{The NWR Recovery Project}

Saragusty et al 2016 offers a road map to NWR recovery. Although strategies can be combined at various stages, it describes essentially three different paths to creating NWRs:

- IVF. Using sperm from Suni, a male who died in 2014, and eggs from Fatu, in vitro fertilization (IVF) was tried in August 2019, resulting in two viable NWR embryos, which are now frozen. The frozen embryos await the conditions for safe implantation into SWRs, who can act as surrogates to bring the embryos to term. Meanwhile, at the San Diego Global Zoo, artificial insemination of prospective SWR surrogates have yielded SWRs named Edward (born July 2019) and Future (born Novemeber 2019).

- Selective breeding. NWR eggs are extremely hard to obtain and obviously scarce, so strategies apart from IVF need to be explored. A second method aims to create hybrids using frozen NWR sperm and SWR eggs. Hybrids could then be selectively bred to match the genetic profile of NWR (Hildebrandt et al 2018).

- Stem cells. The most ambitious method requires dramatic advances in biotechnology. It hopes to construct gametes from stored NWR tissue. The idea is to produce induced pluripotent stem cells from NWR fibroblast cells. From these stem cells one can in principle obtain sperm and ova. Intracytoplasmic sperm injection and embryo transfer into SWRs would then be done, as above. The idea, which may sound like science fiction, is to go from NWR skin cells to full blown NWRs. Although it sounds far-fetched, this kind of process has been carried out with mice in Japan. Artificial gametes were produced from iPSCs from mouse tail and these were then used to produce fertile offspring. So a proof-of-concept already exists.

The most cutting-edge science is being pursued to save the NWR. It involves sophistiocated assisted reproduction techniques, e.g., sperm injection, embryo transfer, as well as pioneering work in stem cell technology. Advances in the science of tissue storage also should not be overlooked, as they play a central role in all three strategies. Along the way scientists are learning a great deal about rhinos' reproductive cycle, fertility and diet. 
The NWR recovery project is the par excellence of technologically innovative conservation, at least as far as methods go. It's about as invasive as it gets: petri dishes, sophisticated tissue freezing, advanced assisted reproductive technology, the development of gametes from skin cells, and even a robot specially designed to navigate the steep switchbacks in the long cervix of the rhino. There is little "natural" about any of that. Advances in biotechnology are a potentially powerful new tool in the new conservationist's toolbox. Now one can imagine using gene drives to eliminate dangerous invasive animals like ship rats on New Zealand islands, genetically rescuing black footed ferrets and chestnut trees, and engineering DNA fragments to recreate long extinct animals (Preston 2018).

While the tools are new the goal is the same traditional one of conservation biology, namely, restoration. What is the goal of NWR recovery projects? The road map answers: "Our ultimate goal, possibly several decades in the future, is to establish viable, selfsustaining northern white rhinoceros populations." The road map doesn't say precisely where the herds will live, but Ryder et al 2020 clarify that the goal is "the reestablishment of one or more breeding populations of NWRs within suitable habitat within their former range (4) and that "[r]estoring rhinos to their historical range is intrinsic to the NWR Intiative" (4). While other side benefits of the program are important and mentioned, restoration to historical range is understood as the main objective that "empowers the other project components" (4). NWRs used to graze on the grasslands of eastern central Africa and we want to restore that state of affairs.

This objective is not defended in any detail, I suspect, because this goal is widely shared and accepted throughout conservation biology. There does not seem to be any special burden here. However, in what follows we'll see that the closeness of the NWR to the SWR creates a kind of tension: the features of NWR that make them scientifically attractive for recovery are the very features that undermine the traditional rationale (and others often advocated). This tension raises important questions about the goals of NWR conservation and even conservation itself.

\section{Challenges to Intervening}

Why should we go to such efforts to restore NWR? Let's begin by dismissing two common justifications, namely, that nature in central Africa is "supposed to" include NWR and that we "owe it" to the species because we're the ones who destroyed them. As many have pointed out, it's hard to make sense of either claim. The first draws a line in shifting sand, highlighting a particular state in a changing ecosystem as a baseline from which to make decisions. It's hard to understand nature herself as picking a particular baseline and infusing it with value. The second asks us to imagine that we can "owe" something to taxa, which demands a novel and controversial ethics to understand how something without interests can be harmed. Instead, let's consider the sorts of rationales mentioned by the NWR recovery project and similar kinds of conservation-oriented initiatives. 


\subsection{Historical Fidelity}

Conservation biology's goal of restoring past states of nature is widely accepted. Recently, however, it has become increasingly scrutinized. That things were a certain way in the past is not itself a justification for interventions seeking to re-create this past state. More needs to be said to explain why restoration is valuable. ${ }^{1}$

What triggered this new focus is the concern that the challenges conservation now faces demand new strategies and a re-assessment of its goals. Climate change, nonpoint source pollution and other non-local threats are some of the largest drivers of environmental destruction. Leaving nature alone can no longer be expected to lead to the restoration of some valued historical baseline. Logging can be prohibited in a particular forest, but the forest won't recover if the climate is changing rapidly; fishing can be eliminated in a marine protected area, but that won't help organisms affected by increasing acidification. The impacts of chemical pollution, micro-plastics, disruption to the nitrogen and phosphorus cycles, aerosol loading, ozone depletion, and more, offer similar challenges. Living in the so-called Anthropocene, it is said, means that we'll sometimes have to "garden" (Marris 2011) more than before.

The challenges just mentioned put pressure on the methods and tools used in traditional conservation. They can also raise questions about the goals. Why restore a species if its contemporary flora and fauna have vanished due to climate change? If ought implies can, then the restored species or ecosystem should be possible, or better, likely, as a result of the intervention.

In many cases there are legitimate concerns that this will not be the case. Climate change and other forces have already changed the world so much that restoration is often no longer possible. The case of possibly bringing back the woolly mammoth is perhaps the most dramatic example where this concern arises. The natural world has obviously changed in innumerable ways since the Pleistocene era. Why bring back the mammoth (or mammoth-like elephant) into this exotic new world, commentators ask, when the world lacks many of the desirable relational features between the mammoth and its nowvanished ecosystem? Mammoth social behavior, mammoth parasites, and mammoth relationship with extinct flora are all irretrievable gone. See Preston 2018, Rowher and Marris 2018, Sandler 2013, Sherkow and Greely 2013, Zimov 2005 for discussion.

Note that in the case of the mammoth we are comparing the desired past state to the present one. However, with a long term project like NWR recovery, we must also look in the other temporal direction and compare the present state of the world to what it will be like when the project is complete. the world is still in flux. This concern is especially warranted here because this project will take a very long time. Indeed, it will take so long that one worries that the goal of NWR restoration is likely to be unattainable for the foreseeable future. Let me explain.

Rhinos take a long time to reach sexual maturity and have gestation periods of 16

\footnotetext{
${ }^{1}$ For example: "Relying on history to justify the proposed end state of a restoration project is problematic because of climate change, knowledge gaps, and the fact that ecosystems are dynamic and have no single historical state" (Rohwer and Marris 2016). See also Sandler 2012's discussion of natural historical value in section 2.4.1.
} 
months. Females space their calving by roughly three to four years. To avoid inbreeding depression we need an effective founder population of close to 50 animals. That is consistent with similar recovery projects such as the Przewalski's Horse Reintroduction Project of China, which began with a release of 55 horses. So it could be a long time ("50 years" Saragusky et al 2016) before we have a viable potential founder population. The range of the NWR includes northwestern Uganda, southern Chad, south-western Sudan, the eastern part of center African Republic, and northeastern Democratic Republic of the Congo (DRC), and they last resided in Garamba National Park, so let's focus there. What will that area look like in 50 years?

It doesn't look great for rhinos. In terms of climate, temperatures are projected to increase by $1-2.5^{\circ} \mathrm{C}$ by 2050 and $3^{\circ} \mathrm{C}$ by 2100 and there will be greater variance in rainfall and its intensity. We should expect more intense rainfall events and longer dry spells. Of particular concern is that projections suggest that "northeastern areas of Zone 2 (particularly around Garamba National Park) will experience a decline in grassland by 2100" (2018 Climate Links). NWRs are the largest grass grazers in the world. The grass, seeds, stems and nuts they eat all require water and they typically live near water sources when possible (Estes, 1991; Groves, 1972; Nowak, 1999). Climate change does not bode well for them in this region.

Perhaps worse, the demand for rhino horn in China and Vietnam is high and expected to increase (Blaine 2013; Oxpeckers 2013). Despite aggressive measures to protect rhinos from poaching, the number poached continues to be alarmingly high. It would be naive to think this will go away or won't increase just because the preferences fueling this demand are not science based. And increased population will seriously exacerbate existing pressures. The population of the DRC is today roughly 87 million people, but DRC has one of the highest growth rates in the world. By 2065, the population is expected to be more than 250 million people (UN World Population Prospects 2019). The pressure from so many people - especially from so many undergoing the hardships brought on by climate change - is bound to lead to more development and habitat destruction as well as greater poverty leading to increased poaching.

The scientists involved in NWR recovery are of course acutely aware of the need to curb poaching, and an anti-poaching program is supposed to be paired with this project. However, the trends are not good. To give an idea of what an uphill battle the rhinos face, note that the prediction model of Haas and Ferreira 2016 finds a serious risk of extinction for $S W R$ starting in 2036. Because the NWR is already functionally extinct they do not consider NWR. But if SWR - whose herd numbers 20,000 - is at risk of extinction in 2036, that does not bode well for a much smaller population of 50 in (say) 2080 in a geography more susceptible to the ravages of climate change and poaching.

When we map the rhino timeline on to likely projections about populations, climate and poaching, it leads to a gloomy forecast: if traditional restoration is the goal, it's unlikely to be met for a very long time. It's not at all clear that the goal is achievable in the foreseeable future. 


\subsection{Ecosystem Health}

Another prominent justification for the restoration of threatened or extinct species appeals to the role they play in an ecosystem. This justification is often used in the de-extinction literature, so perhaps it applies here too. Wooly mammoths once roamed the northern tundra. Like its close relative the elephant it was presumably a keystone species, a species whose interactions have disproportionate effects on an ecosystem. The re-introduction of the wolves into Yellowstone National Park shows how their impact on elk and coyotes can have an unexpectedly large and positive indirect impact on the ecosystem. The idea in the case of the mammoth is that the North needs its elephant back (Zimov 2005). Can the NWR project be justified in a similar way?

Let's put the depressing point of Section 3.1 to one side, as well as worries about what factors exactly determines an ecosystem's health. Maybe there is an urgency to get NWR back into their historical range for the ecosystem health of this section of central Africa?

There is little doubt that the largest grazer on the planet is a keystone species. Cromsigt et al 2018 write that "the white rhinoceros is the only remaining megagrazer with impacts across the landscape," extending from effects on soil and nutrients to climate. This massive impact can in turn be expected to provide ecosystem services such as fire prevention and climate change mitigation, among many others. When at full population, the NWR was likely one of the greatest of all keystone species, however one makes precise that concept.

That said, filling the large grazer role can't be the goal of NWR recovery. If that were the (sole) goal one could move SWR into the historical habitats of NWR and skip all the biotechnology. The reason is that the SWR can do what the NWR did.

While Groves et al 2010 hold that SWR and NWR should be classified as two different species and point to some dental and craniometric differences, the majority view is that they are subspecies (Harley et al 2016, using complete mitochondrial genomes, and Tunstall et al 2018, using a genome-wide analysis). Crucially, no one has found significant differences in their morphology or behavior. Cinková and Policht 2014 found statistically significant differences in some acoustic signals, in particular, pant calls. But this result (sadly) was necessarily based on small $N$, and it's hardly clear that signaling differences make an important difference in terms of ecosystem health.

White rhinos are the most social of all rhinos. The different social cultures between SWR and NWR might have made a behavioral difference that mattered in a significant way to the ecosystem. Unfortunately all that information is gone. Fatu and Najin were born in captivity. In fact, to help them adjust to their move to Ol Pejeta Conservancy a SWR was introduced to help them learn how to behave in the wild (Anderson 2021). Behavioral differences based on learning have vanished.

While this point is controversial and requires further study, I think it is fair to say that one cannot point to a difference between NWR and SWR and claim that the feature in question is indispensable for some important aspect of ecosystem health or some ecosystem service. One cannot say that the NWR can provide in Central Africa what SWR cannot. That is perhaps one the reasons why we don't hear appeal to the important ecosystem services NWRs would provide. SWRs cannot generally be moved to NWR 
range because poaching makes it unsafe for them, not because SWRs wouldn't do the ecological engineering NWRs do.

\subsection{Biodiversity}

Of course the main goal of conservation is biodiversity. Even if we cannot reintroduce the NWR into their historical range, keeping the line intact prevents biodiversity loss. One need not repopulate NWR in their historical range. The Australian Rhino Project, for example, seeks to establish an insurance population of NWR in Australia. That project has been criticized as "colonial conservation" (Hayward et al 2018), and the whole idea of long term ex situ conservation raises many other questions due to its conflict with the goal of historical fidelity. All of this deserves more discussion, but let's keep to the present focus. Surely conserving biodiversity is a reason to promote NWR recovery?

It may be, but again the closeness of the NWR to SWR raises hard questions. As is well-known to philosophers and others concerned with the foundations of conservation, spelling out exactly what biodiversity is and why we should value it can be challenging (for a recent survey, see Newman, Varner and Linquist 2018). This is especially the case for preserving subspecies as opposed to species, as the former do not carve a biological "joint in nature" the way the latter do.

Some have argued that the value of biodiversity partly is due to keeping characteristic and magnificent traits around (Russow 1981; Sober 1986). Others argue that the awe magnificent animals inspire in us is of deep value (Sherkow and Greely 2013). Due to the existence of the SWR, we can't appeal to the goal of trait preservation or the awe that these magnificent creatures produce in us as rationales for restoration. As is the case with their being keystone species, there is no doubt that NWRs meet both criteria-and easily so. NWR have some of the most distinctive and amazing traits imaginable. Every aspect of their morphology is incredible. People who spend time with them often come away with a profound sense of awe. Anderson 2021 makes this case well. Yet every single one of these features is shared with the SWR, who inspire just as much awe and possess the same distinctive and amazing traits.

In this respect, the present case of the SWR and NWR is different than that of many other examples where one wants to conserve subspecies. For instance, Northwestern wolves (Canis lupus occidentalis) and Mexican gray wolves (Canis lupus bailey) are both members of the same species. Should the Mexican subspecies be actively preserved because it is under threat? Should inter-breeding be prevented? Opinions differ. But one powerful driver behind the feeling that the Mexican wolf should be preserved as a distinct subspecies is that the two wolves have very different traits. The Northwestern wolf is (among other differences) much larger and differently colored than the Mexican wolf. Meanwhile, the NWR doesn't have special traits compared to the SWR that can be singled out to justify NWR restoration.

Of course one can appeal to genetic differences as valuable. I will do so in a moment, but not in the way relevant here. The way to reliably tell the difference between the two subspecies of white rhino is by looking at their genomes. Genetic studies show that they diverged from each other approximately 10-80 kya (Tunstall et al 2018), like many other 
African mammal subspecies during the interglacial era. Now, genetic distance does not perfectly covary with species- or sub-species-hood, nor the traits we care about. But often conservationists want to preserve the "genetic integrity" of subspecies nonetheless. This desire is behind the widespread conservation norm against allowing species or subspecies to mix and hybridize, e.g., Scottish wildcats and domestic cats, wolves and dogs. This idea is controversial because it doesn't seem like "integrity" should be an end in itself (Rowher and Marris 2015). For the moment let's just note that the NWR and SWR differ by only $0.1 \%$ of their genome (Tunstall et al 2018). If that difference alone created a duty to conserve - if we had an obligation to preserve all groups differing by just that much - it would completely change conservation.

In sum, the most common rationales for restoration don't easily fit the case of the NWR. We're aren't likely to put the NWR back where it once roamed anything soon, and it shares with the SWR the traits and ecosystem services that make them so valuable. Conservation efforts to save close subspecies are already often controversial, so heroic efforts to recover one so close to another requires even more scrutiny. Scientifically, the similarity between NWR and SWR makes the recovery project attractive. It means that SWR can function as good surrogates for NWR embryos without as much risk as in other cases (and without incurring so much additional ethical concern about imposing that risk). However, this very similarity undercuts most of the traditional rationales for NWR recovery. ${ }^{2}$

\section{Defending the NWR Project}

For advocates of NWR recovery the previous section has been grim. Not everyone will agree with all the points made; however, I believe that I've shown that by the traditional standards and goals of conservation, the NWR rhino recovery project faces an uphill justificatory battle. Because it additionally does nothing to attack the root causes of biodiversity loss and can't possibly be scaled up to deal with the magnitude of this loss, it opens itself to criticism.

That makes the question of whether there are other reasons to engage in the NWR project an urgent one. Are there? I think that one can answer affirmatively and that it's important to do so lest the project be measured by the wrong goals. In what follows I offer two considerations in favor of the NWR recovery even if historical restoration cannot be achieved. These considerations are not decisive. I am not saying that all-thingsconsidered we have a duty to recover NWR. But there are some compelling reasons to do so. The key to appreciating both arguments is a kind of about-face: instead of focusing so much on the specialness or value of the NWR, concentrate instead on what it can do for others.

${ }^{2}$ Mordecai Ogada, a biologist and conservation activist, regards the extinction of the northern white rhino as a kind of hoax designed to bring in more donor contributions to conservation. "Splitting species," he says, "creates an illusion of crisis" (quoted in Lenin 2018). My point is similar: although SWR and NWR may or may not be different species, they are so similar that they don't differ (much) in terms of what we value about white rhinos. 


\subsection{Genetic Rescue of White Rhino}

Rhinos worldwide are in grave danger. The SWR is the only sub-species doing at all well. The recovery of the population to $\sim 20,000$ animals is correctly reported as a conservation success. Nonetheless, the road ahead looks bleak. As we saw, poaching continues and is even expected to increase. Long-term trends about population and climate change are hardly rosy. The prediction model of Haas and Ferreira 2016 finds a serious risk of extinction for SWR starting in 2036. The International Union for Conservation of Nature status of the white rhino remains Near Threatened (2011 assessment).

Worse, the population of SWR isn't particularly genetically varied. When the southern herd split from the northern one, this occurred just as or after the population plummeted (presumably for the same reason many other African mammals did at that time), so the southern herd began with only $\sim 2800$ animals. After rising, the herd crashed dramatically in the late nineteenth century. In 1880 they were erroneously thought to be extinct. All current SWRs originate from this tiny population of 20-50 animals. As we know from experience with the cheetah, genetic loss need not severely limit the rate of population increase. Cheetahs faced a very tight bottleneck approximately 10 kya and yet rebounded to number in the hundreds of thousands at one point. Population size doesn't say everything about the health of a species. Inbreeding and low genetic variability are associated with a number of ills. Genetic variation is nature's insurance policy. It helps protect against rare recessive genetic abnormalities and is a way to spread one's bets on different genes protecting against potentially harmful infectious agents. The SWR is not out of the woods.

Indeed, recent investigations indicate inbreeding may become a bigger problem going forward (Kretzschmar et al 2019). Due to development and other factors, the habitat of the SWR is becoming increasing fragmented. Fragmentation prevents good gene flow through the population. In addition, we've recently learned that female SWR have sexual preferences for individual males, returning to them disproportionately for mating. Together, habitat fragmentation and preferences for certain partners may worsen the genetic diversity of the SWR herd.

Suppose we discovered a hidden valley in India containing a sub-population of cheetah that diverged from extant cheetah 10kya or more. (The Indian subspecies of cheetah existed and is now extinct.) Suppose that subspecies was itself more diverse and less inbred than currently extant cheetah. For the conservation of the cheetah, this would be like hitting a gold mine. It would be imperative to protect this newly found population - not just for its own sake but for the sake of the species.

That is more or less the situation we find ourselves in today, except the subspecies of NWR exists not in a hidden valley but mostly in vials of frozen tissue. In genetic studies of variation, NWR genomes revealed 4,065,345 unique sites (single nucleotide polymorphisms) compared to 2,511,658 for SWRs (Saragusty et al 2016). And in a measure of inbreeding - runs of homozygosity - SWRs turn out to be slightly more inbred than NWRs. We're in the curious situation of having more genetic diversity of white rhino in two living NWR plus frozen tissue than in a population of 20,000 SWR. To me, that the gold mine is frozen doesn't make a moral difference. 
What could we do with this treasure? Not only does it allow us to potentially bring back the NWR, but it might allow us to help the SWR if it ever needs it. Suppose the SWR begins to suffer dramatically, as predicted. One option would be conservation by hybridization, or intentional genetic introgression, i.e., crossing SWR with NWR to increase genetic diversity.

To be open to intentional genetic introgression one must let go a bit of "pure" conservation. Hybridization is often viewed as the enemy in conservation. It takes two groups and makes them one, reducing biodiversity in some sense. It obliterates the "genetic integrity" of each group. The drive to preserve "genetic integrity" in efforts to eliminate cattle DNA from bison, and the attempt in the UK to drive out the ruddy duck are examples of this idea (Rohwer and Marris 2015). With this philosophy in the background and the focus on "bringing back" the NWR, the possibility of conservation by intentional genetic introgression is rarely put in a positive light.

But it can work. As an example, consider the rescue of the Florida panther (Puma concolor coryi). The population in the early 1990's had dwindled to 20-30, had poor genetic diversity, and many individuals presented signs of inbreeding depression. Despite the reservations of many ecologists, in 1995 ecologists and Fish \& Wildlife Services introduced eight female mountain lions from Texas (Puma concolor stanleyana). Five of the females had kittens. Today there is strong evidence that the genetic introgression worked: the population and genetic diversity of the Florida subspecies are up and signs of inbreeding depression are down (van de Kerk et al 2019). Intentional genetic introgression has worked on many animals, including big horn sheep, adders, and prairie chicken.

There are worries that outbreeding depression will accompany genetic introgression. This effect seems to be most common in plants, not large vertebrates. In their genetic analysis Moodley et al 2018 found evidence of post-divergence secondary contact between NWR and SWR. For them, this "increases the likelihood that hybrid rescue could be positive." Circumstances change, but that they reproduced successfully with one another before suggests it might work again. If outbreeding depression did occur, obviously that would be a reason to stop any interbreeding. But as Harley et al 2016 write, "nothing is to be gained by failing to undertake the experiment."

I'm not saying genetic introgression should be done when we get NWR. I'm pointing out that given the threats SWR face, it's an "option price" (see below) worth paying.

The recent birth of Elizabeth Ann, a black-footed ferret cloned from a black-footed ferret who lived more than 30 years ago, is an example of an intervention in this neighborhood. Black-footed ferrets descended from just seven individuals, which gives them poor genetic diversity and susceptibility to disease. The clone from frozen tissue held at San Diego Zoo Global can potentially help with both challenges.

Why not keep the NWR "herd" frozen until needed, as was done with the black-footed ferret? The current rationale doesn't yet provide a reason to create full NWRs as opposed to hybrids, nor a reason to produce a separate NWR herd. The clearest reasons to do will come from my second rationale (section 4.2). That said, I think one can see reasons to create a separate viable NWR herd consistent with the current line of thought. After all, a separate viable rhino herd can of course grow in size and also evolve due to local 
environmental pressures, increasing both abundance and diversity. And splitting rather than lumping together genetically different subpopulations provides further insurance against catastrophe. Two separate populations getting increasing diverse from each other is likely better than one hybridized population.

Stevenson et al write that conservation "should try to maximize options and minimize regrets" $(1992,11)$. That is my first rational for NWR recovery. The white rhino is valuable in every way an animal can be, both for anthropocentric and non-anthropocentric reasons. As the largest hindgut fermenter, pseudo-ruminant megagrazer, it has unique effects on its ecosystem and possesses some of the most charismatic and awe inspiring traits in all the animal kingdom. It ticks all the boxes. Given that, I want to preserve roughly what economists call option value (Maclauren and Sterelney 2008) regarding white rhino. Option value is the amount one is willing to pay to keep an option alive in the future. A viable healthy population of NWR gives conservationists more options to preserve the species. To see this, it helps to focus less on the hard-to-defend distinctiveness of NWR and more on the good of the species, Ceratotherium simum.

\subsection{The Ark Argument}

Critics of de-extinction projects like the mammoth often decry these efforts as about the science, not the conservation. It is a technofix, creating a "gee whiz" factor that will attract grants and fame for labs - it is not about saving animals or the environment. Here is Diehm 2017 expressing this kind of sentiment:

At bottom, de-extinction is more experimental and novelty-producing than it is restitutive or restorative; its ideal is less a call for humans to scale things down to make room for other forms of life than it is a summons to keep scaling up our technological and managerial interventions in their worlds. It is this feature of de-extinction that is most inescapable...and it is for this reason that it is so deeply objectionable (27).

Worse, for some, it gives "the impression that extinction is reversible" and "diminishes the gravity of the human annihilation of the species" (Campagna et al 2017). Not only is de-extinction not a benefit, it is a bad policy because we will not properly atone for or learn from our crimes.

Although there are large differences between the NWR project and the targets of these criticisms, one can imagine many of these opinions being voiced also about NWR recovery. Here I want to agree with the critics that to some extent this project is about the science and not NWR, but I want to cast the situation in a more positive light than they do. If we again perform an about-face and look at the project as not primarily about the NWR, then we're able to see the larger and more positive picture. So even if we agree with Ogada (see footnote 2) that the "extinction" of the NWR is a kind of manufactured crisis, we may still find value in the recovery project.

Cyrobanks that store the tissue of endangered animals are often compared to Noah's Ark. The Frozen Zoo, run by the San Diego Global Zoo, is regularly described as an Ark in the press and the UK's Frozen Ark is explicitly named with it in mind. I don't think 
we can properly evaluate the ethics of NWR recovery without taking this Ark metaphor seriously.

We are facing unprecedented destruction of the animal kingdom due to the twin disasters of climate change and biodiversity loss. If we focus on mammals, land and marine, we learn that human activity has decreased wild mammals to only $4.2 \%$ of total mammal biomass (Bar-On et al 2018). All the rest is composed of human beings (35.9\%) and our livestock $(59.9 \%)$. As the climate, pollution and land fragmentation worsen, this small number will only get smaller. We face a very grim future, one where almost all mammals not supported by human beings have vanished. The water is metaphorically and literally rising.

Suppose human beings emerge from this dark period. Soule et al 1986 estimate that it will be approximately a millennium before wildlife density begins to increase-and that estimate was before worries about the climate became so relevant. Mammals will be in very short supply in this time. But they will be needed and wanted. We can conceive of the need and desire in either non-anthropocentric or anthropocentric terms. For the sake of brevity let's focus on desire understood as the preferences of future generations of human beings. We can be relatively certain that future humans will have a strong desire for mammals. This will be for both instrumental reasons (e.g., what wolves contribute to valued ecosystems) or intrinsic ones (e.g., humans have always had a strong affinity with mammals).

If we can transfer some mammals to the future-or the opportunities for particular mammals-we will be doing future human beings a great service. Some traditional conservationists often don't like to include anthropocentric preferences in conservation decisions. But to the question of the Introduction -who is NWR recovery good for- it is hard to deny that future generations of human beings is one clear defensible answer. Others will also benefit. These include animals and ecosystems, which each may benefit in innumerable ways. The argument is therefore not strictly anthropocentric in nature.

Another group that may benefit are current researchers. Today's scientists, if successful, may bring in more grants and donations with this work, increasing their reputational standing (and all that goes with that) in the process. This fact makes some science studies scholars and conservation activists suspicious of projects like this (see above). In the Introduction I ask who is the project for and mention researchers as one possible answer. However, it strikes me as overly reductive to judge the project in terms of individual rewards. Many laudable projects confer benefits upon those who pursue them; if these are the only reasons to pursue a project, one should look at it skeptcially. However, if human beings survive the coming flood, they will be grateful for the chance at recovering any part of the animal kingdom; the motivations of individual scientists will be of much less importance.

If the reader agrees with the reasoning so far, then the only step that remains is to acknowledge that developing the science behind NWR recovery will advance the goal of increasing teh chances of conveying mammals to the future. That this is so is beyond dispute. In a world of mammal scarcity, all of these technologies will be important - IVF, cryobanking, selective breeding, and especially obtaining gametes from frozen tissue. If the most ambitious technology surrounding stem cells is developed, this will be 
utterly transformative for the future. The NWR must be one of the most scientifically challenging species of mammal one could choose for this technology. If it succeeds here, that will not mean it will work elsewhere but it will vastly improve the chances of it doing so.

Moreover, this point answers the question from the previous section about why developing a viable herd of NWR is necessary (as opposed to keeping tissue in storage wanting for hybridization or cloning). If we can give future generations not only frozen tissue but also the knowledge and ability to transform it into viable populations, that would be the better gift. The science of creating self-sustaining animal populations is still in its infancy. We have a lot to learn, and bringing back the NWR is an opportunity that will teach us much of value.

The critics are right: a lot of this is about the science and not the animal. The NWR is not chosen as the first functional de-extinction project for "pure" conservation reasons. It is not so special when compared to the SWR, nor does it currently play an important role in its native habitat. Instead, it is a great candidate for the effort because we have diversity in the frozen tissue and because the NWR is so similar to the SWR. That makes surrogacy and other steps in the process much more likely to succeed (and succeed more ethically, given serious ethical worries about very distant animals acting as surrogates). And this effort succeeding is crucially important, for if it succeeds we likely can place many others animals on the Ark, animals whose conservation value is unimpeachable. Giving the future a chance with mammals will not make up for anything that was done or address the main causes of biodiversity loss. Yet with this science and enough genetic tissue we could bequeath to the future the possibility of founder populations of some of what we most value in nature's riches. ${ }^{3}$

\section{Conclusion}

The commentary on the NWR rhino project, for and against, is about rescuing the NWR. The narrative treats the NWR like the icon of conservation, the panda, an endangered animal, but one whose fate will go from doomed to possibly recovered by technology. This spin is natural given the tragic story. However, due to the SWR, the NWR is not like the panda. And characterizing the situation this way sets almost unattainable goals for the project as measured by traditional conservation.

The criticism is therefore natural. Moderate critics of de-extinction projects point out that they will not scale up to the size of the biodiversity crisis. "If we really want to take heroic steps to save species," writes Sandler 2013, "the best way - by far - is to change our lifestyles and our eco-social systems." As a consequence, he considers de-extinction an instance of "luxury conservation," permissible so long as it doesn't detract from more important interventions. We can imagine a similar point made in the present context. Why go through all this trouble - a giant technofix - when the goal of a self-sustaining

\footnotetext{
${ }^{3}$ For this reason I think we should heed with urgency the 1992 Convention on Biological Diversity's recommendation that we freeze more animal tissue. It would be tragic if we develop the ability to save endangered mammal populations but lack the tissue diversity necessary to do so effectively.
} 
herd is hardly likely, the NWR is not so special compared to the SWR, and the root causes are not addressed?

I've suggested that we zoom out and focus on saving the white rhino, the species, as opposed to NWR. When we do that and consider our goal of delivering non-domestic mammals to the future, the recovery initiative looks less like a luxury and more like a necessity. It is true that developing technology will not tackle the root causes of biodiversity loss. That requires, as Sandler notes, changing our entire economic and social structures. Poaching occurs due to massive inequality. If we wait for that to be alleviated (if it ever will be), then our chances of bequeathing currently rare mammals to the future plummets. If I am right, pursuing this technology is something we should do to preserve option value regarding the white rhino and to help deliver mammals to the future.

These are the main reasons why we should save the NWR. We shouldn't save the NWR because future generations will care about having it in addition to the SWR. We should save it because it is part of building the Ark, not so much because it may be a passenger on it. This opportunity is the last gift of the NWR. ${ }^{4}$

\section{References}

[1] Anderson, S. 2021. The Last Two Northern White Rhinos on Earth. New York Times. Published on Jan 6, 2021.

[2] Bar-On YM, Phillips R, Milo R. 2018. The Biomass Distribution on Earth. Proc Natl Acad Sci 115, 6506-6511.

[3] Blaine, S. (Sep. 17, 2013). Vietnam's Market for Rhino Horn Could Quadruple, Business Day. Available: www.bdlive.co.za/national/science/2013/09/17/vietnamsmarket-for- rhino-horn-could-quadruple

[4] Campagna, C. et al. 2017. De-scenting Extinction: The Promise of De-extinction May Hasten Continuing Extinctions. Hastings Center Report 47, S48-S53.

[5] Cinková I, Policht R. 2014. Contact Calls of the Northern and Southern White Rhinoceros Allow for Individual and Species Identification. PLoS ONE 9, e98475

[6] Cromsigt JPGM, te Beest M, Kerley GIH, Landman M, le Roux E, Smith FA. 2018. Trophic Rewilding as a Climate Change Mitigation Strategy? Phil. Trans. R. Soc. B 373, 20170440.

[7] Diehm, C. 2017. De-extinction and Deep Questions About Species Conservation, Ethics, Policy \& Environment 20, 25-28

\footnotetext{
${ }^{4}$ Thanks to students in both graduate and undergraduate philosophy seminars at UC San Diego and to members of a lunchtime talk at the Institute for Practical Ethics for discussion. For written comments, I thank Jonathan Cohen, Yasha Rohwer, Ronald Sandler, Elliott Sober, Eric Winsberg, and two anonymous referees. These discussions and comments were all amazingly helpful.
} 
[8] Gilcrist, J. 2018. The Northern White Rhino Should Not Be Brought Backto-Life. The Conversation. http://theconversation.com/the-northern-white-rhinoshould-not-be-brought-back-to-life-94153.

[9] Groves CP, Fernando P, Robovsky’ J. 2010. The Sixth Rhino: a Taxonomic Reassessment of the Critically Endangered Northern White Rhinoceros. PLoS ONE 5, e9703.

[10] Haas, T. and Ferreira, S. 2016. Conservation Risks: When Will Rhinos be Extinct? IEEE Transactions on Cybernetics 46, 1721-1734.

[11] Harley, E. et al. 2016. Comparison of Whole Mitochondrial Genome Sequences of Northern and Southern White Rhinoceroses (Ceratotherium simum): the Conservation Consequences of Species Definitions. Conservation Genetics 17.

[12] Hayward, M. W., Ripple, W. J., Kerley, G. I., Landman, M. , Plotz, R. D. and Garnett, S. T. 2018. Neocolonial Conservation: Is Moving Rhinos to Australia Conservation or Intellectual Property Loss. Conservation Letters 11, e12354.

[13] Katz, E.1992. The Big Lie: Human Restoration of Nature. Res Philos Technol 12, 231-241.

[14] Kretzschmar, P, Auld, H, Boag, P. 2019. Mate Choice, Reproductive Success and Inbreeding in White Rhinoceros: New Insights for Conservation Management. Evol Appl. 00, 1-16.

[15] Lenin, J. 2018. Was The Death Of The Last Male Northern White Rhino The End Of A Hoax? The Wire. Accessed at: https://thewire.in/environment/was-the-death-ofthe-last-male-northern-white-rhino-more-blood-on-our-hands-or-the-end-of-a-hoax.

[16] Maclaurin, J. \& Sterelny, K. 2008. What is Biodiversity? University of Chicago Press.

[17] Marris, E. 2011. Rambunctious Garden: Saving Nature in a Post-Wild World. NY: Bloomsbury.

[18] Marris, E. 2014. 'New Conservation' is an Expansion of Approaches, Not an Ethical Orientation. Anim Conserv 17, 516-517.

[19] Marris, E. 2017. Cut and Paste Conservation. https://urldefense.com/v3/__https://magazine.scu.edu/magazines/spring2017/cut-paste-conservation/__;!!Mih3wA!UKfh6_9TQ9IhmgTcuBCCEdBhk3aG_uKFBugfdABJjcO2Rq3URx0NXcphBpqk8H0gg\$

[20] Minteer, B.A. 2019. The Fall of the World: Extinction, De-extinction, and the Ethics of Conservation. NY: Columbia University Press. 
[21] Moodley, Y. Russo, I-R, Robovský, J., Dalton, D., Kotze, A., Smith, S., Stejskal, J., Ryder, O., Hermes, R., Walzer, C., and M. Bruford. 2018. Contrasting Evolutionary History, Anthropogenic Declines and Genetic Contact in the Northern and Southern White Rhinoceros (Ceratotherium simum ). Proceedings of the Royal Society B: Biological Sciences. 285.

[22] Newman, J., Varner, G., \& Linquist, S. 2017. Defending Biodiversity: Environmental Science and Ethics. Cambridge University Press.

[23] Oxpeckers Reporters. 2013. China's Growing Appetite for Rhino Horn, African Sentinel. Available: www.africansentinel.net/China-s-growing- appetite-for-rhino.html.

[24] Preston, C. 2018. The Synthetic Age: Outdesigning Evolution, Resurrecting Species, and Reengineering Our World. MIT Press.

[25] Rohwer, Y. and Marris, E. 2015. Is There a Prima Facie Duty to Preserve Genetic Integrity in Conservation Biology? Ethics, Policy $\mathscr{E}$ Environment 18, 233-247.

[26] Rohwer, Y. and Marris, E. 2016. Renaming restoration: conceptualizing and justifying the activity as a restoration of lost moral value rather than a return to a previous state. Restoration Ecology.

[27] Rohwer, Y., and Marris, E. 2018. An Analysis of Potential Ethical Justifications for Mammoth De-extinction and a Call for Empirical Research. Ethics, Policy \&6 Environment 21(1), 127-142.

[28] Russow, L.-M. 1981. Why Do Species Matter? Environmental Ethics 3, 101-112.

[29] Ryder, O. A., Friese, C., Greely, H.T., Sandler, R., Saragusty, J., Durrant, B.S., and Redford, K. 2020. Exploring the Limits of Saving a Subspecies: The Ethics and Social Dynamics of Restoring Northern White Rhinos, Conservation Science 86 Practice 2, e241.

[30] Sandler, R. L. 2012. The Ethics of Species: An Introduction. Cambridge University Press.

[31] Sandler, R. L. 2013. The Ethics of Reviving Long Extinct Species. Conservation Biology 28, 354-60.

[32] Sandler, R. L. 2017. De-extinction and Conservation Genetics in the Anthropocene. Hastings Center Report 47, S43-S47.

[33] Saragusty, J. et al. 2016. Rewinding the Process of Mammalian Extinction. Zoo Biology 35, 280-292.

[34] Sherkow, J. S. and Greely, H. T. 2013. What If Extinction is Not Forever? Science 340, 32-33. 
[35] Sober, E. 1986. Philosophical Problems for Environmentalism, in Bryan G. Norton (ed.), The Preservation of Species: The Value of Biological Diversity, Princeton, NJ and Guildford, UK: Princeton University Press, 173-19.

[36] Soulé M et al. 1986. The Millenium Ark: How Long a Voyage, How Many Staterooms, How Many Passengers? Zoo Biology 5, 101-113.

[37] Tunstall et al. 2018. Evaluating Recovery Potential of the Northern White Rhinoceros from Cryopreserved Somatic Cells. Genome Res 28, 780-788.

[38] van de, Kerk, M. Onorato, D.P., Hostetler, J.A., Bolker, B.M. and Oli, M.Ket al. 2019. Dynamics, Persistence, and Genetic Management of the Endangered Florida Panther Population. Wild. Mon. 203, 3-35.

[39] Yinon M. Bar-On, Rob Phillips, Ron Milo. 2018. The Biomass Distribution on Earth. Proceedings of the National Academy of Sciences 115, 6506-6511.

[40] Zimov, S.A. 2005. Pleistocene Park: Return of the Mammoth's Ecosystem. Science 308, 796-798. 